\title{
改扩建公路路线设计的探讨
}

\author{
刘广发 \\ 中公实业工程咨询(吉林)有限公司 \\ DOI:10.32629/btr.v3i1.2830
}

[摘 要] 随着经济与社会的快速发展,我国很多地区的公路出现通畅能力不足、等级过低等问题,公路改扩建工程因此大量涌现。基于此,本文 将深入探讨改扩建公路路线的设计,望提供参考。

[关键词] 改扩建公路; 路线; 设计

\section{1 原公路路线存在问题分析}

1. 1 街道间隔较短

现代城市经济与功能体系的不断完善受传统地方规划影响, 通常在公 路设计之初并未考虑到城市如今的发展现状, 因此就极易造成城市内街道 间隔较短, 极易出现车流汇聚或堵塞的状况, 自然难以满足大车流通行的 需要, 同时也为后续城市经济体系的持续构建造成了阻碍。因此, 根据地方 城市可持续发展的需求, 在改扩建设计过程中, 必须根据城市分区与交通 需求对道路通行状况进行重新规划, 确保将改扩建工程经济成本消耗降到 最低, 且满足车辆通行安全性的要求, 才能为后续城市经济交流平台的构 建提供更全面的保障。

\section{2路基病害较多}

原有城市公路体系构建寿命较长, 在水土环境变动等多方面影响下, 路基已经难以满足大荷载运输的需求, 甚至部分地区地下环境已经出现空 洞与岛状冻土等情况, 如果无法及时解决以上问题, 就极易对车辆通行造 成影响, 甚至引发交通用事故。另外, 在公路路线设计工作中, 设计者必须 根据场地状况展开设计, 在判断路线设计是否符合城市交通功能需求的同 时, 也同样需要借助岩土质量的等报告分析可能对道路整体性与质量性造 成的影响, 以便为后续改扩建工程的开展提供数据保障。

\section{3 桥梁搭接问题}

桥梁是城市交通体系中较为重要的组成部分, 不但为城市与城市之 间提供了高效的交通渠道, 同时更为经济平台的构建奠定了坚实的基 础。但从现有城市公路系统状况来看, 桥梁通常会根据城市交通要求进 行定期检修, 并且在宽度与承载力方面都有不同程度的加强, 因此即便 是同一时期修建的公路与桥梁, 在现代功能体系构建需求的影响下, 都 势必会在承载力和道路宽度等问题上出现差异, 如此当桥梁车辆进入公 路系统时, 就极易对路面及基础造成过度损耗, 由于公路沉降等因素的
影响, 桥梁与公路还会出现高差等问题, 这就为车辆的正常行驶安全埋 下了隐患。

\section{2 改扩建公路路线的设计分析}

2.1 平面设计

在改扩建公路路线的平面设计中, 为有效改善公路交通能力, 保证改 扩建工程的高效快捷完成, 线路设计必须得到重点关注, 公路路线方案的 选择则属于其中的关键, 直接影响改扩建工程的效果。一般情况下, 设计师 需基于能直则直、能曲则曲、顺势而为、整体协调、直圆配合的原则进行 改扩建公路的平面设计, 因地制宜的设计构思选择也需要得到重视, 以此 结合相关标准要求、性能需要, 即可保证改扩建公路路线设计不会出现设 计线性突变问题。

为保证设计质量, 技术指标的合理选用必须得到重视, 如改扩建公路 工程平面设计的直线、圆曲线, 具体设计要点如下: (1) 直线设计。结合相 关研究可以发现, 很多国家对公路直线长度存在一定要求, 如德国规定公 路直线最大长度不得超过 $20 \mathrm{~V}$, 我国现阶段的公路线路设计规范同样规定 直线长度不宜过长, 但值得注意的是, 为保证线形连续性, 应尽量避免直线 过短情况出现, 且同向圆曲线间最小直线长度 (以m计) 以不小于设计速度 (以 $\mathrm{km} / \mathrm{h}$ 计) 的6倍为宜, 反向圆曲线间最小直线长度 (以m计) 以不小于设计 速度 (以 $\mathrm{km} / \mathrm{h}$ 计) 的 2 倍为宜, 改扩建公路的设计时应尽量满足。此外, 在同 向曲线的设计中, 如其最大长度不足 $6 \mathrm{~V}$, 设计人员需针对性采用方法进行 修正, 如采用单一曲线进行牵连进行两端曲线修正, 或采用半径相当大的 圆曲线替代直线段, 为提高线路流畅性, 还可以采用卵型曲线。如反向曲线 的长度不足 $2 \mathrm{~V}$, 可采用使夹直线长度达到 $2 \mathrm{~V}$ 或合并成 “ $\mathrm{S}$ ” 型曲线的设计; (2) 圆曲线设计。在最小、最大圆曲线半径路线设计中, 圆曲线的设置不应 受制于公路平面转角大小的影响。在现有公路的改扩建工程中, 均需要设 置圆曲线并充分利用原有公路路线, 但这不可避免地会导致圆曲线半径偏

频广播节目的所有流程。

在广播电台融媒体直播机房设计实现之后, 观众不但能够看到主持 人、嘉宾, 也能够与他们互动、交流。根据有关统计, 广播电台播出《行风 热线》节目之后, 新颖的广播视频直播方式吸引了大量观众互动, 而且创造 了广播新媒体互动新纪录。近些年来, 传统广播电视媒体的发展每况日下, 而 “广播+电视+网络” 的融媒体为广播媒体发展注入了新鲜血液, 使得广 播电视媒体焕发了新活力。

广播电台融媒体直播机房的设计与实现, 虽然取得了良好的效果, 但 是视频广播具体实践时仍然暴露出了许多不足, 比如参与视频广播的工作 者大多是传统广播技术人员, 他们对于视频节目的录制并不是很了解, 而 且缺少实践经验, 很容易发生镜头切换不到位等问题。与此同时, 在进行视 频广播时仍然采用的是传统广播方式, 片花广告播放、热线电话等都以音

频为主, 观众通过视频只能看到主持人、嘉宾的一些动作, 而且还会感到不 是很自然。针对一系列的不足, 还需要广播电台工作人员一同努力, 不断地 进行探索、研究与创新, 全方面提升视频广播效果。

\section{[参考文献]}

[1]张霄.新形势下地方广播电视台融媒体发展的思考与应对策略 [J]. 传播力研究,2017,1(09):69.

[2]李随红.新疆人民广播电台网络流媒体直播系统的设计与实现 [J]. 中国有线电视,2018,(11):1303-1305.

[3]毛明杰,周健,张挺,等.无锡广播电视台高清融媒体虚拟演播室设计 与实施 $[J]$.现代电视技术,2016,(10): 77-80.

[4]郭静.内容创新,赋予新技术丰沛的生命力一 《中国声音中国年》 (2016版)的创新启示[J].中国广播,2017,(05):88-93. 
小, 为避免横向加速度对驾驶者与乘客带来较为负面影响, 设计人员需 基于设计规范中圆曲线最小半径完成平面设计。当采用 $9000 \mathrm{~m}$ 以上的圆 曲线半径时, 视线集中的 $300 \sim 600 \mathrm{~m}$ 范围内的视觉效果基本等同于直线, 这必须得到重视,一般情况下圆曲线半径需控制在 $10000 \mathrm{~m}$ 内。条件限制 在公路改扩建工程中较为常见, 圆曲线半径与设计时速不应因此违背 规范要求。基于 《公路路线设计规范》(JTGD20-2017) 要求, 在改扩建 公路工程的平曲线与圆曲线长度设计中, 需保证平曲线能够满足 $3 \mathrm{~s}$ 的 行程, 并结合工程实际, 因地置业的选择曲线长度。而在缓和曲线长度 的确定中, 设计人员需同时关注线形与视觉美学所需的长度、超高渐变 率所需的长度、离心加速度变化率所需的长度、操作汽车方向盘所需 的长度。

2. 2改扩建公路纵断面设计分析

在落实改扩建公路纵断面设计过程中, 设计人员必须根据地方岩土 质量与原有地质环境进行分析, 判定道路等级与最高承载力极限, 同时 还应该对原有公路承载环境进行检测, 已鉴定公路基础与路面是否可持 续利用, 以便拟定后续道路设计方案。纵断面设计目的是根据公路运输 要求判断道路高差、沉降系数、基土环境、承载面是否满足交通运行需 要, 通过图纸说明公路基层处理的措施与完善方案。因此,在改扩建公路 纵断面设计过程中, 设计人员必须指派专业的测量人员到达现场, 对现 有公路高程进行检测, 确定其中有明显破损或沉降差异数值后判定原有 地下基础状况, 再选择有效地加强补偿方案, 将基础沉降系数降低。例如, 部分工程中如果发现道路路面及基础均不满足道路正常运行的要求, 则 可以尝试将路面材料回收再加工, 而后刨除原有路基系统, 根据现阶段 公路承载力与宽度要求重新设计基础环境, 再将路面材料重新摊铺, 就 能够满足公路基本的使用要求, 同时更满足了改扩建工程经济性的需 要。另外, 在与地方桥梁搭接的过程中, 检测人员应将桥梁结构与相邻公 路的沉降数据提供给设计单位, 以便后续公路设计过程中能够有效地降
低二者高程差异, 避免对公路交通质量造成损害, 同时也可以借助压型 钢板等材料在桥面与路面之间搭设缓冲平台, 避免车辆行驶出现颠籍等 问题, 以保护居民的出行安全。

2.3改扩建公路横断面设计分析

改扩建公路横断面设计应根据其使用要求和当地的自然条件 (包括地 质、水文和材料情况等) 结合施工方案进行设计, 应既有足够的强度和稳定 性, 又要经济合理。影响路基强度和稳定性的地面水和地下水, 必须采取措 施进行拦截, 并结合路基排水和附近农田灌溉综合考虑, 做好排水设计, 使 之形成完整的排水系统。

在横断面设计时, 应充分考虑原有公路两侧现状, 确定采用单侧加宽 还是双侧加宽。一般来讲路面单侧加宽较好施工, 在施工过程中, 只对原有 公路的一侧进行开挖或填筑路基。但如果老路两侧都有林带或者不便于拆 迁的电杆等地物, 而老路两侧地物之间的距离又满足双侧加宽的条件时, 为避免大规模的砍伐或者拆迁, 就要选择双侧加宽的方式。

\section{3 结束语}

改扩建公路设计要点在城市规划中的有效落实, 不但能够根据城市规 划内容提供更经济的交通调控方案, 由此满足经济与功能体系构建完善的 需要, 同时凭借设计内容, 更能够根据通行要求加强公路高程等数据的把 控力, 以此降低公路交通事故出现的概率。

\section{[参考文献]}

[1]李季增. 高速公路改扩建桥梁设计要点分析 [J]. 交通世 界,2017,(10):104-105.

[2]陈康俊.改扩建高速公路的路线设计原则及要点分析 [J].城市道桥 与防洪,2017,(04):22-24+6.

[3]刘晓南.高速公路改扩建桥梁设计要点分析[J].公路交通科技(应用 技术版),2018,14(01):252-253. 